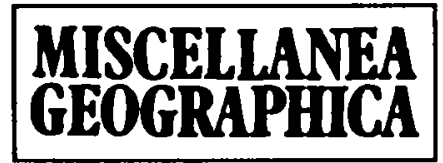

WARSZAWA 1992 Vol. 5

Jerzy Siwek

\title{
ON SOME RELIABILITY FACTORS IN CARTOGRAPHIC RESEARCH
}

It is common to perceive maps first of all as forms of representation of objects and phenomena. The second - research - function of maps is not so well perceived.

The factors which influence the reliability of the process of cartographic study are the following: formulation of research purpose adequate for the capacities of a map, reliability of the source maps, skills of the persons involved, methods of data measurement and of their processing, parameters and efficiency of technical devices, ways of presentation of research results and possibility of their verification. Evaluation of reliability is connected with the search for errors which are brought about by succesive stages of research, which are contained in each source material and in each procedure. This requires answering the question as to when, where and due to what causes these errors arise. Finding out and location of the errors creates the possibility of their minimization or even of avoiding them, and therefore - of an increase in the reliability of research.

Difinition of the essence of errors appearing during cartographic studies shall be facilitated if we consider them against a background of structure of cartographic method of research. This structure is formed by three planes: 1 .substantial - studying concrete phenomena and processes, 2. cartographic - resulting from accepting maps as the only sources of information and often even as the form of presentation of research results, 3. technical - resulting from the use of non-cartographic methods in measurement and transformation of the contents of maps (Siwek 1984).

It is possible to avoid substantial errors if source materials are adequately evaluated and selected, and if a person involved is appropriately skilled. That is why the question of substantial correctness - although of paramount importance for reliability of research conducted - shall not constitute the subject of further considerations here.

The most numerous errors in all kinds of activities based upon maps are of cartographic nature. They result from cartographic projections and from methods of cartographic presentation and generalization. Negative effects which are brought about by cartographic convention are from the very cartographic point of view regarded as mere limitations, being the price for adoption of this particular 
convention, and are considered along with advantages resulting from this. Thus, one should treat as errors only deviations from the commonly accepted rules, such as selection of improper projection or of wrong parameters, application of methods of presentation inadequate for the contents in question, wrongly performed generalization, location of elements of contents not corresponding to graphical precision etc.

From among the three sources of cartographical crrors it is generalization that may constitute a particular hazard. If generalization is a part of research procedure, its place in this procedure is of foremost importance. Let us take, for example, elaboration of a map of land slope inclinations on the scale of 1:100 000 on the basis of topographical map on the scale of 1:10 000. There are two ways of fulfilling this task: 1) generalization of surface relief to the scale of 1:100 000 and execution of the map of slopes on this scale, and 2) elaboration of the map of slopes on the scale of 1:10 000 and then its generalization to the scale of 1:100 000. Images thereby obtained - in spite of application of the same slope inclination classes - are distinctly different (see Figs. 1B and 1C). By comparing it with the initial map (Fig. 1A) we can conclude that the second procedure is correct - i.e. the one with generalization placed in the final part of the research process (Fig. 1C). Visual impression is confirmed by calculation of the rank correlation coefficient between the values of slope inclination magnitudes on the map of 1:10,000 and 1:100,000 (calculated on the basis of the grid of elementary fields). This coefficient is in the first case equal only to 0.40 and in the second case to 0.95 . The risk related to the choice of the first procedure (Fig. 1B), especially when the person making the map has little experience, arises from the significant economy of time acquired in this way.

The example outlined shows the essential significance of the place assigned to generalization in the research procedure. The sequence of steps leading finally to generalization should not, though, be treated as a stiff rule. According to the purpose and the kind of task to be fulfilled this sequence could be reversed. Thus, for instance, in the study of correlation performed at the beginning (i.e. before transformation) generalization facilitates grasping of interrelations existing among phenomena. This is so because cartographic image of phenomena is freed of details which often "mask" the regularitics of spatial distribution. The correlation map resulting from transformation of such an image may therefore better reflect these regularities. This was demonstrated experimentally by A.M. Berlant (1986).

The weakest link of the cartographic research method is, though, the very transformation of the contents of maps, thus belonging to the technical plane. Approaches used for that purpose originate from various disciplines of science (e.g. from mathematical statistics or information theory), and their value cannot be always uniquely evaluated in spite of formal adaptation for cartographic purposes. The longer and the more complex the process of transformation of source data (maps), the more difficult or even impossible - in the sense of uniqueness - is the evaluation. 


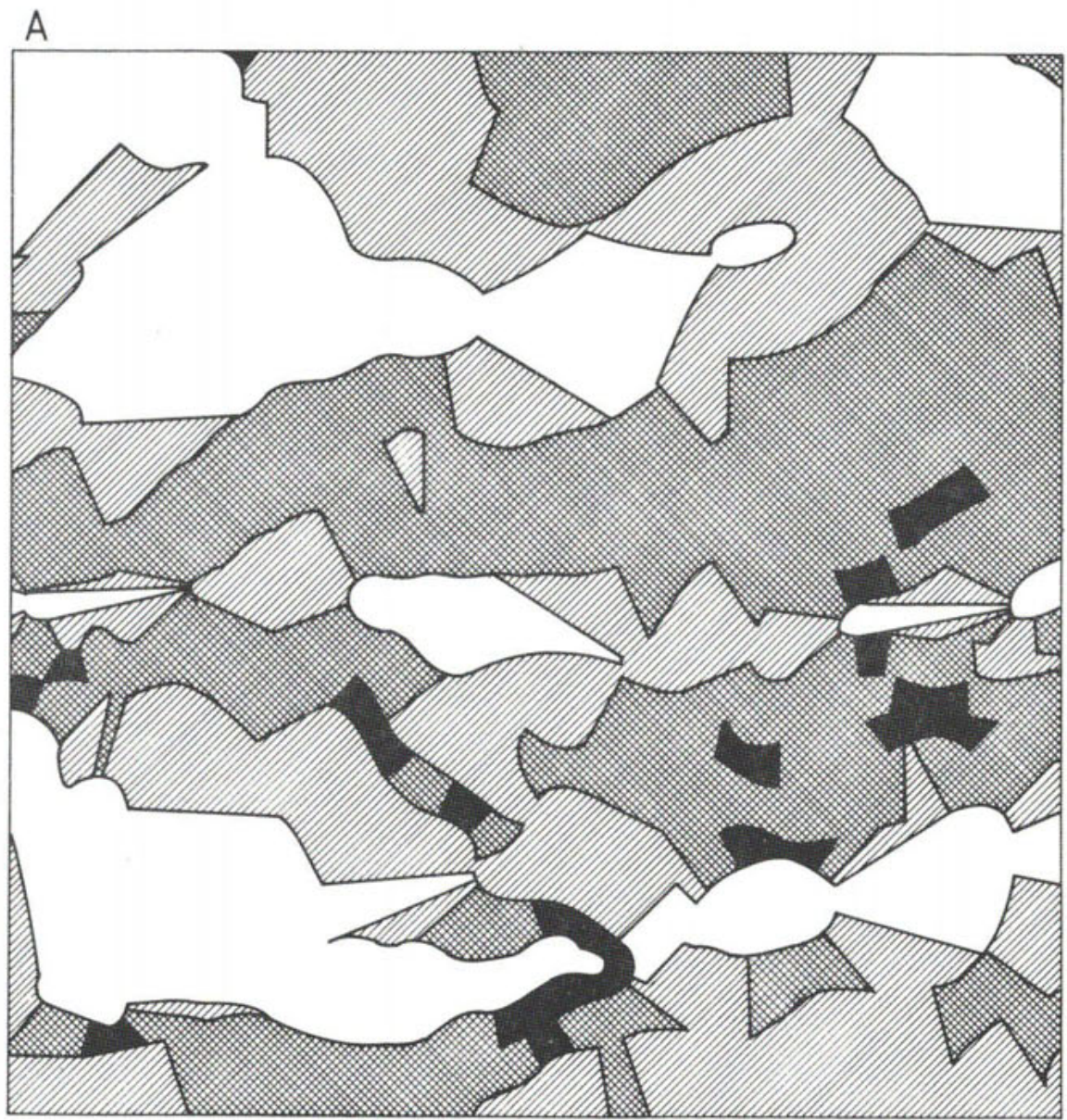

\section{SLOPE ANGELS}

B

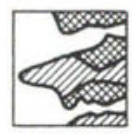

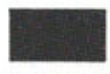

$2-5^{\circ}$
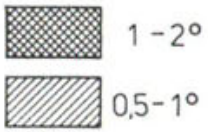

$<0,5^{\circ}$

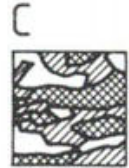

cosereses

Fig. 1. A - map of slope inclinations, 1:10,000, elaborated on the basis of a topographical map on the same scale; B - map of slope inclinations, 1:100,000, elaborated on the basis of a topographical map on the same scale $\left(r_{\mathrm{AB}}=0.40\right)$; $\mathrm{C}$ - map of slope inclinations, 1:100,000, elaborated as generalization of map A $\left(r_{\mathrm{AC}}=0.95\right)$. 

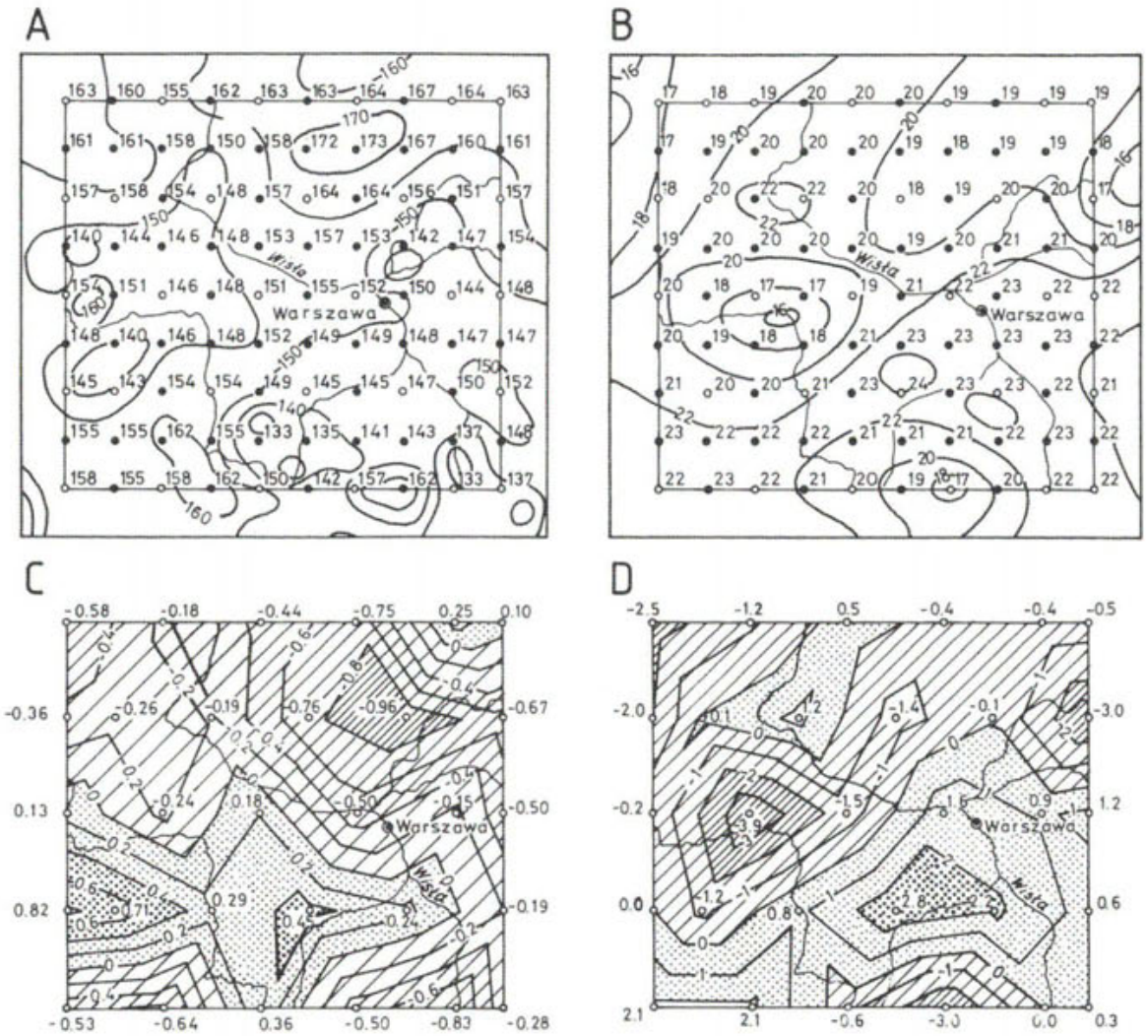

Fig. 2. A - average number of days with precipitation; B - average number of days with a storm (on the basis of "Narodowy Atlas Polski" - National Atlas of Poland); C - distribution of correlation coefficient for phenomena A and B: D - distribution of residuals from regression of phenomenon B with respect to phenomenon $A$.

To support this proposal let us take the example of the study of interrrelation of precipitation and storms in the area of central Poland (Fig. 2A and 2B). Map 2C, elaborated with the method given by A.M. Berlant (1986), shows the distribution of the coefficient of correlation of the two phenomena. Determination of correctness of the image obtained is difficult, for comparison with reality or with a detailed source map cannot be done (correlation is, by all means, not a really existing entity). The only, indirect, method of verification is to conduct a multi-method study involving comparisons. In order to do this another map was prepared (Fig. 2D), where the adopted measure of dependence are residuals from regression, expressed in per cent (according to the method given by A.H. Robinson and R.A. Bryson). Significant differences between the two maps make a reliable determination of relations between precipitation and storms impossible. The differences, when perceived from the point of view of mathematical statistics, may of course be justified by application of various measures of dependence. 
This does not change the fact, though, that in the case referred to in this paper the multi-method way of verification of results of a cartographic study misses the point.

Considerations presented, concerning reliability of studies based upon maps are, of course, incomplete. The intention of the paper was to outline the problem which only recently became the subject of cartographic literature.

\section{REFERENCES}

Berlant A.M., 1986 Obraz prostranstva: karta $i$ informaciya (The image of space: the map and the information), Moskva, Mysl.

Robinson A.H., Bryson R.A., 1957. "A method for describing quantitatively the correspondence of geographical distributions", Annals of the Association of American Geographers, Vol. 47, No. 4.

Si wek J., 1984, "Rozważania nad kartograficzną metodą badań" (Some thoughts on the cartographic method of research) in: Teoretyczne i metodyczne problemy wspótczesnej kartografii. "Materialy Ogólnopolskich Konferencji Kartograficznych, Vol. 10, Lublin. 
